\title{
Monoclonal Antibody Specific for Histone H1 Phosphorylated by Cyclin-Dependent Kinases: A Novel Immunohistochemical Probe of Proliferation and Neoplasia
}

David E. Burstein, Shimon Oami, Francine Dembitzer, Caryn Chu, Georgeta Cernaianu, Anatoly Leytin, Ecaterina Misilim, Subba Rao Jammula, James Strauchen, D. Stave Kohtz

Department of Pathology (SO, FD, CC, GC, AL, EM, SRJ) and Derald H. Ruttenberg Cancer Center (DEB, JS, DSK), Mount Sinai School of Medicine, New York, New York

Monoclonal antibody 12D11 (MAb 12D11) has been shown to bind histone $\mathrm{Hl}$ isolated from human placenta and other tissues but not histone $\mathrm{Hl}$ that has been digested with bacterial alkaline phosphatase. We show here that phosphorylation of phosphatase-treated histone $\mathrm{Hl}$ with cyclin dependent-kinase (CDK) restores binding by MAb 12D11. We conclude that MAb 12D11 selectively binds histone $\mathrm{Hl}$ that has been phosphorylated by CDKs, and we have investigated the use of MAb $12 D 11$ as an immunohistochemical probe of CDK activity in situ. Previous immunofluorescence studies have revealed strong nuclear staining by MAb $12 D 11$ in proliferating cultured cells and the absence of staining in terminally differentiated cells. Immunohistochemical staining of frozen and formalin-fixed, paraffin-embedded sections of benign tissues with MAb 12D11 was nuclear and confined to recognized foci of cell proliferation. In lymphoid germinal centers, MAb 12D11 preferentially stained large lymphoid cells with a relative lack of staining in small cleaved cells, contrasting with a lack of cell size discrimination observed with the monoclonal antibody proliferation probe, MIB-1. Tumor tissues displayed strong albeit heterogeneous staining of malignant cells by MAb 12D11, with little or no staining observed in surrounding nonneoplastic stromal cells. Differential staining by MAb 12D11 of invasive and in situ carcinoma sug-

Copyright (C) 2002 by The United States and Canadian Academy of Pathology, Inc.

VOL. 15, NO. 7, P. 705, 2002 Printed in the U.S.A

Date of acceptance: March 13, 2002.

Portions of this research were presented in abstract form at the meeting of the United States and Canadian Academy of Pathology (1997), and the joint meeting for the Japanese and American Societies for Cancer Research (1998).

This work was supported by National Institutes of Health Grant CA72775 (D.S.K.) and a Mount Sinai Breast Resource grant (D.E.B.).

Address reprint requests to: D. Stave Kohtz, Department of Pathology, Box

1194, Mount Sinai School of Medicine, 1 Gustave Levy Place, New York,

NY 10029; e-mail: stave.kohtz@mssm.edu; fax: 212-534-7491. gest applications in prognostication. MAb 12D11 may also be useful in identification of tumors more likely to respond to therapeutic CDK inhibitors.

KEY WORDS: Cell cycle, Cyclin-dependent kinases, Histone H1, Immunohistochemistry, Phosphorylation-specific antibodies, Proliferation markers, Tumor markers.

Mod Pathol 2002;15(7):705-711

Proliferation of both normal and neoplastic cells is marked by important changes in the expression and posttranslational modification of cell cycle and other regulatory proteins. Despite recent progress made in understanding the molecular basis of cell proliferation, the potential use of immunohistochemical staining of proliferation markers as a tool for tumor diagnosis and prognostication has been only partially explored. Presently, monoclonal antibodies (MAbs) MIB-1 and Ki-67, which detect a nuclear protein of unknown function, are used most commonly to identify actively proliferating normal and neoplastic cells in tissue sections (1). Other proliferation markers, including proliferating cell nuclear antigen (PCNA; for review, see (2)), topoisomerase II (3) and cyclins (4) also have been employed with some success. Each of these has specific disadvantages: The target of MAb MIB-1 is a protein of virtually unknown function, and does not appear to bind selectively in any specific phase of the cell cycle (1). PCNA has a long half-life, and may persist in cells which have become quiescent (5). Some cyclins are expressed at significant levels in nondividing cells $(6-11)$. Other markers such as topoisomerase II appear promising, but evidence of their clinical utility awaits more extensive testing.

In a previous report, it was shown that MAb 12D11 specifically binds mammalian histone H1, and that binding of the antibody could be eliminated by digesting histone $\mathrm{H} 1$ with bacterial alka- 
line phosphatase (12). Immunofluorescence microscopy of cultured cells revealed that MAb 12D11 stains the nuclei of proliferating primary human skeletal myoblasts, but antibody binding was eliminated upon terminal differentiation (12). In this report, we show that phosphorylation of phosphatase-digested human histone $\mathrm{Hl}$ with cyclindependent kinase (CDK), but not the other kinases that were tested, restores antigen binding to $\mathrm{MAb}$ 12D11. From these data, we have concluded that MAb 12D11 binds specifically to histone $\mathrm{H} 1$ that has been phosphorylated by active CDKs. Activation of CDKs is an essential event for progression through the cell cycle (13-17), and several studies have shown that histone $\mathrm{H} 1$ is phosphorylated significantly during the $\mathrm{S}$ and $\mathrm{M}$ phases of the cycle (18-20). Because histone $\mathrm{Hl}$ is an abundant protein present in the nuclei of virtually all vertebrate cells, we investigated the use of MAb 12D11 as a marker of cell proliferation in normal and neoplastic tissues.

\section{MATERIALS AND METHODS}

\section{Cell Culture and Reagents}

Mouse hybridoma cells producing MAb 12D11 were cultured in DME medium containing $4.5 \mathrm{~g} / \mathrm{L}$ of glucose and $10 \%$ fetal bovine serum. Hybridoma supernatants containing approximately $20 \mu \mathrm{g} / \mathrm{mL}$ of MAb 12D11 were produced by growing hybridoma cells to maximum density and removing the cells by centrifugation. Horseradish perroxidase-coupled goat anti-mouse IgM was from Boehringer Mannheim. Bacterial alkaline phosphatase was from Calbiochem. A multilink streptavidin-biotin immunoperoxidase staining kit was from BioGenex (catalog \#QP900-9L.)

\section{Kinase Reactions and Western Blotting}

Histone $\mathrm{H} 1$ was purified from human placenta by acid extraction and acetone precipitation (11). Histone $\mathrm{H} 1$ was digested with $25 \mathrm{U}$ of bacterial alkaline phosphatase (BAP) in $50 \mathrm{~mm}$ Tris ( $\mathrm{pH}$ 8.3), 1 $\mathrm{mm} \mathrm{MgCl}_{2}$, and $0.1 \mathrm{~mm} \mathrm{ZnCl}_{2}$ to remove serine and threonine phosphate groups. Histone $\mathrm{Hl}$ treated with BAP was isolated by acid extraction and acetone precipitation, then dissolved in water. To phosphorylate BAP-treated histone $\mathrm{H1}, 5 \mu \mathrm{g}$ of substrate was incubated in $25 \mathrm{~mm}$ HEPES, $10 \mathrm{~mm}$ $\mathrm{MgCl}_{2}, 50 \mathrm{~mm} \mathrm{NaCl}, 50 \mu \mathrm{M}$ ATP, and kinase. CyclicAMP-dependent kinase (protein kinase A) catalytic subunit (Sigma), casein kinase (Sigma), or cyclin A/E-CDK2 purified from rat liver (gift of Tom Langan, University of Health Sciences Center, Denver) were incubated in $20 \mathrm{uL}$ total reaction volume at $30^{\circ}$ $\mathrm{C}$ for 20 minutes. Reactions and sham reactions

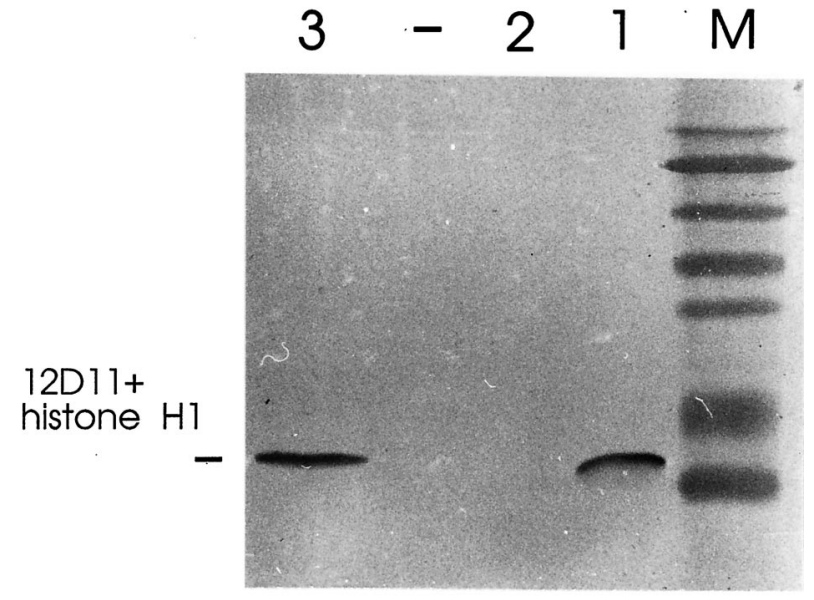

FIGURE 1. Binding of MAb $12 \mathrm{D} 11$ to histone $\mathrm{H} 1$ is dependent on phosphorylation by cyclin-dependent kinase. Samples of human placental histone $\mathrm{H} 1$ were isolated by acid extraction and acetone precipitation, resolved by SDS-PAGE, and analyzed by Western blot with MAb 12D11. Lanes: M, markers: (top to bottom, Mr 180K, 116K,

$84 \mathrm{~K}, 58 \mathrm{~K}, 48.5 \mathrm{~K}, 36.5 \mathrm{~K}, 26.5 \mathrm{~K})$. Lane 1, Five micrograms human placental histone H1. Lane 2, Five micrograms human placental histone H1, digested with bacterial alkaline phosphatase. Lane 3, Five micrograms human placental histone $\mathrm{H1}$, treated first with bacterial alkaline phosphatase, then phosphorylated by cyclin-dependent kinase.

lacking ATP were stopped by the addition of EDTA to $50 \mathrm{~mm}$, and histones were isolated by acid extraction and acetone precipitation.

Samples were resolved by sodium dodecyl sulfate polyacrylamide gel electrophoresis (SDS-PAGE), then transferred electrophoretically to nitrocellulose filters. The blots were fixed with $10 \%$ acetic acid $/ 25 \%$ isopropanol, washed several times with water, and blocked with 5\% nonfat dry milk in 25 $\mathrm{mm}$ Tris (pH 7.4) and $150 \mathrm{~mm} \mathrm{NaCl}$ (TBS). The blots were incubated with MAb 12D11 (full-strength hybridoma supernatant supplemented with $5 \%$ nonfat dry milk and $0.5 \%$ Tween 20 ) for 18 hours at $4^{\circ}$ C. The blots were washed twice in TBS supplemented with $0.5 \%$ Tween 20 (TBS-Tween), then incubated for 2 hours $\left(4^{\circ} \mathrm{C}\right)$ with horseradish peroxidase-coupled goat anti-mouse IgM in TBSTween supplemented with $1 \%$ bovine serum albumin. The blots were washed three times with TBSTween, then developed with $1 \mathrm{mg} / \mathrm{mL}$ 4-chloro-1naphthol (BioRad) in TBS supplemented with $20 \%$ methanol and $0.015 \%$ hydrogen peroxide.

\section{Frozen Sections}

Frozen sections were stained using a two-step immunoperoxidase staining protocol. Sections on polylysine-treated slides were fixed in $2.5 \%$ formalin for 10 to 40 minutes, washed three times with phosphate buffered saline (PBS), incubated with MAb 12D11 hybridoma supernatant diluted 1:1-3 in PBS supplemented with $0.75 \mathrm{M} \mathrm{NaCl}, 5 \%$ horse serum (HS), and $5 \%$ nonfat dry milk. The sections were incubated with primary antibody for 2 hours 
at $37^{\circ} \mathrm{C}$, then washed four times with PBS supplemented with $0.75 \mathrm{~m} \mathrm{NaCl}$. The sections were incubated with horseradish peroxidase-labeled goat anti-mouse IgM second antibody in PBS supplemented with $1 \%$ bovine serum albumin for 1.5 hours at $37^{\circ} \mathrm{C}$. The sections were then washed four times with PBS, then developed in PBS with diaminobenzidine $(1 \mathrm{mg} / \mathrm{mL})$ and hydrogen peroxide $(0.015 \%)$.

\section{Formalin-Fixed, Paraffin-Embedded Sections}

Sections $(5 \mu \mathrm{m})$ were prepared from archival, formalin-fixed, paraffin-embedded surgical pathology specimens. Sections were prepared using an antigen-retrieval method (21), followed by streptavidin-biotin staining. Paraffin was removed from sections in xylene followed by graded alcohols. Endogenous peroxidase activity was blocked with $3 \% \mathrm{H}_{2} \mathrm{O}_{2}$ for 15 minutes, and sections were washed with water. Antigen retrieval was performed as follows: sections were heated to $90^{\circ} \mathrm{C}$ for 15 minutes in $0.01 \mathrm{M}$ citric acid buffer, $\mathrm{pH} 6.0$, then cooled to room temperature for 20 minutes. Sections were washed with PBS, then incubated with MAb12D11 culture supernatant, 1:20 dilution, in PBS supplemented with $0.75 \mathrm{M} \mathrm{NaCl}, 5 \%$ casein, and $5 \%$ horse serum for either 1 hour at $37^{\circ} \mathrm{C}$ or overnight at ambient temperature. Sections were washed four times in PBS, then incubated with a multilink biotinylated anti-immunoglobulin (BioGenex) for $20 \mathrm{~min}$ utes at ambient temperature. The sections were washed four times with PBS, then incubated with streptavidin-coupled horseradish peroxidase (BioGenex) for 20 minutes at ambient temperature. The sections were then washed four times, developed with diaminobenzidine (see above) for 20 minutes, then washed in water for 5 minutes. Some slides were counterstained with hematoxylin, and all slides were then dehydrated through graded alcohols and xylene and coverslipped.

For MIB-1, standard antigen retrieval and staining methods were used: slides were exposed to 0.11 M sodium citrate, $\mathrm{pH} 6.0$, at $100^{\circ} \mathrm{C}$ for 5 minutes, cooled for 20 minutes, and washed with PBS. Sections were then incubated overnight at ambient temperature with MIB-1 diluted 1:10-1:20 in PBS supplemented with $2.5 \%$ nonfat dry milk, $5 \%$ goat serum, and $0.2 \%$ bovine serum albumin. Slides were washed in PBS, then processed for immunodetection with a streptavidin-biotin immunoperoxidase kit and diaminobenzidine, as above.

Benign proliferative tissues studied included colon, small intestine, and tonsils. Tumors studied included adenocarcinomas of mammary, endometrial, ovarian and colonic origin, head and neck squamous carcinomas, and non-Hodgkin's lymphomas.

\section{RESULTS}

MAb 12D11 Specifically Binds Histone H1 that Has Been Phosphorylated by Cyclin-Dependent Kinases

Human histone $\mathrm{H} 1$ was isolated from placenta and analyzed by Western blot with MAb 12D11. Consistent with previous results (12), MAb 12D11, and IgM, bound the upper, slower migrating band in the mammalian histone H1 doublet (Fig. 1, Lane 1). Also consistent with previous observations (12), digestion of histone $\mathrm{H} 1$ with bacterial alkaline phosphatase (BAP) ablated binding by MAb 12D11 (Fig. 1, Lane 2). When BAP-digested histone $\mathrm{H} 1$ was phosphorylated with a mixture of cyclin A/CDK2 and cyclin $\mathrm{E} / \mathrm{CDK} 2$ isolated from regenerating rat liver, binding to MAb 12D11 was recovered (Fig. 1, Lane 3). In contrast, phosphorylation of BAPdigested histone $\mathrm{H} 1$ by either protein kinase $\mathrm{A}$ or casein kinase I did not restore binding to MAb 12D11 (data not shown). Together, these results show that MAb 12D11 does not bind unphosphorylated histone $\mathrm{H} 1$ and specifically binds histone $\mathrm{H} 1$ that has been phosphorylated by cyclin-dependent kinases.

\section{Immunostaining of Benign Tissues}

Frozen and routinely processed formalin-fixed, paraffin-embedded sections of benign tissue from colon, small intestine, and tonsils were stained with MAb 12D11. In colon (Fig. 2, A-B) and small intestine (data not shown), staining was confined to nuclei of cells at the base of glandular epithelium, the site of epithelial mitogenesis (22). The pattern of staining of colon crypt epithelial nuclei with MAb 12D11 was qualitatively similar, but quantitatively lower than immunostaining by MIB-1/Ki-67 (Fig. 2, A-B).

Prominent nuclear staining with MAb 12D11 was noted in lymphoid germinal centers in colonic Peyer's patches (data not shown) and in germinal centers in reactive tonsillar/adenoidal lymphoid tissue (Fig. 2C). MAb 12D11 differed from MIB-1 staining in benign lymphoid tissue (Fig. 2D) in several respects: 1) The number of MAb 12D11-positive cells within germinal centers was consistently lower than the number of MIB-1-positive cells (Fig. 2, C-F). 2) A peripheral zonal staining pattern was often more readily apparent in MAb 12D11-stained germinal centers than it was with MIB-1-staining (Fig. 2, C-D), corresponding well to the zone of mitogenesis (23). 3) Large activated lymphocytes were preferentially stained by Mab 12D11, with relative sparing or weak, equivocal staining of small cleaved lymphocytes. In contrast, MIB-1 stained both cell types (Fig. 2, E-F). This suggests that MAb 12D11 staining more effectively discriminates sub- 

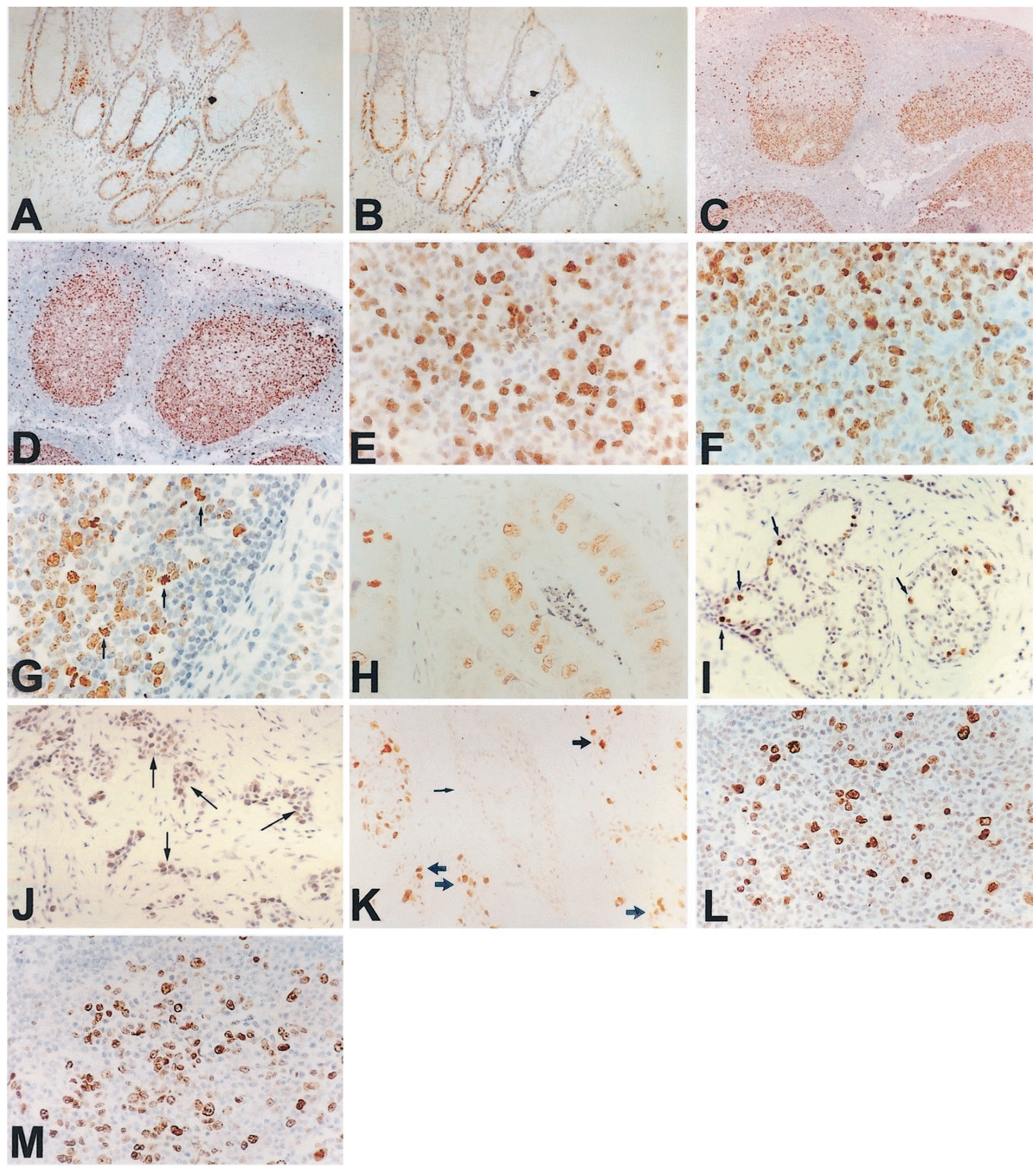

FIGURE 2. MAb 12D11 and MIB-1 immunoperoxidase staining. A, Benign colonic epithelium. MAb 12D11, formalin-fixed, paraffin-embedded. B, Benign colonic epithelium, parallel section. MIB-1. C, E, Benign adenoidal/tonsillar tissue, MAb 12D11, formalin-fixed, paraffin-embedded. C, Low power; E, high power. D, F, Benign adenoidal/tonsillar tissue, MIB-1, parallel section. D, Low power; F, high power. G, Benign adenoidal/tonsillar tissue, MAb 12D11: fragmented nuclei, high power (see arrows). H, Colonic adenocarcinoma, MAb 12D11, formalin-fixed, paraffin-embedded, high power. I, Mammary carcinoma. MAb 12D11, frozen section, formalin-fixed, counterstained with hematoxylin. Arrows, Scattered positively stained nuclei in intraductal carcinoma, cribriform type, mostly at periphery of duct. J, Mammary carcinoma, same specimen as (I), area of invasive carcinoma, MAb 12D11. Note greater percentage of positively stained cells than in intraductal component in (I) (see arrows). K, Mammary carcinoma, same specimen as (I) and (J), no counterstain. MAb 12D11. Note intraductal area (thin arrow) and invasive nests (thick arrows). L, Follicular lymphoma, mixed small cleaved and large cell type. MAb 12D11, formalin-fixed, paraffin-embedded. M, Follicular lymphoma, mixed small cleaved and large cell type, parallel section. MIB-1. 
sets of activated germinal center lymphocytes than does staining with MIB-1. In parafollicular regions, both MAb 12D11 and MIB-1 selectively stained scattered large immunoblast-like cells. Germinal centers from other benign lymphoid populations, including reactive lymph nodes and Hashimoto's thyroiditis, showed similar findings (data not shown). Staining of fragmented nuclei by $\mathrm{MAb}$ 12D11 was noted in some germinal centers Fig. 2G), possibly represents with cells undergoing apoptosis, a common event in germinal centers (24). In contrast, nuclear fragments in necrotic regions of tumors did not stain with MAb 12D11 (data not shown).

\section{Immunostaining of Malignant Cells}

Adenocarcinomas of mammary, endometrial, ovarian and colonic origin, head and neck squamous carcinomas, and non-Hodgkin's lymphomas were stained with MAb 12D11. Staining was more prominent in the neoplastic cells of tumors, with nonstaining or focal weak staining of nonneoplastic tumor stromal cells, tumor vessel endothelium, and tumor-infiltrating leukocytes (Fig. 2H). The percentage of MAb 12D11-positive nuclei varied between tumors of the same histopathologic type, suggesting heterogeneity in the degree of CDKmediated histone $\mathrm{H} 1$ phosphorylation within specific histopathologic categories. Heterogeneity was also observed between different regions of the same tumor, probably associated with cell cycle phase and/or differences in the rates of cell division. In one case of cribriform-type intraductal carcinoma, staining was confined to occasional cells, most at the periphery of the duct. However, adjacent nests of infiltrating carcinoma cells showed a considerably higher percentage of positively staining nuclei than the noninvasive component of the tumor (Fig. 2 , I-K). This suggests that MAb $12 \mathrm{D} 11$ may distinguish invasive malignant cells from preinvasive neoplasia in certain tumors. However, the basis for this distinction may be differences in proliferation rates between in situ and invasive tumor components. Nuclear debris in necrotic areas of comedo carcinoma was nonstaining with MAb 12D11 (data not shown), contrasting with positive staining of fragmented nuclei in benign cells in lymphoid germinal centers that may represent cells undergoing apoptosis.

Several aspects of MAb 12D11 staining of nonHodgkin's lymphomas were consistent with the patterns observed in benign lymphoid tissue. Preferential staining of large rather than small lymphoid cells by MAb 12D11 was observed in lymphoid malignancies as well. In several cases of follicular lymphoma, for example, MAb 12D11 preferentially stained large lymphoid cells in con- trast to MIB-1 that stained both large and small cells (Fig. 2, L-M). As in benign tissue, the percentage of lymphoma cell nuclei stained by MAb 12D11 was consistently lower than the percentage stained with MIB-1. In small lymphocytic lymphoma, MAb 12D11 staining was confined to the larger lymphoid cells that are present in loose aggregates (pseudofollicular proliferation centers) and are believed to represent the proliferative component of this neoplasm (25). In contrast, the predominant population of small cells, which is believed to accumulate but not divide, was nonstaining (data not shown).

\section{DISCUSSION}

The role of MIB-1 and other markers such as PCNA in predicting tumor behavior has been the subject of numerous studies. Unlike the target proteins of other proliferation probes such as MIB-1, which are expressed in proliferative states but are absent in quiescent states, histone $\mathrm{H} 1$ is ubiquitously expressed, independent of the state of cell division. However, phosphorylation of histone $\mathrm{H} 1$ at CDK sites clearly does correlates with cell proliferation (12). We present evidence that MAb 12D11, which detects CDK-phosphorylated histone $\mathrm{H1}$, is a novel immunohistochemical probe of proliferation. The biochemical and biological basis of MAb 12D11 as a probe of proliferation and/or prognosis rests upon its ability to detect histone $\mathrm{Hl}$ only when phosphorylated by CDKs.

$\checkmark$ The immunohistochemical staining properties of MAb 12D11 are entirely consistent with the known expression and activation properties of the cyclin-dependent kinases (CDKs). CDKs are a set of related kinases that govern the highly regulated sequence of cellular events which underlie entry into and progression through the cell cycle (for reviews, see Refs. 13-17). Cyclins are the regulatory subunits of the cyclin-dependent kinases, and are expressed differentially during the cell cycle. The $G_{1}$ cyclins include the D-type cyclins and cyclin $\mathrm{E}$, which form active complexes with CDK4 and 6 and CDK2, respectively (26-28). CDK4 and 6 bound to D-type cyclins do not have histone $\mathrm{H} 1$ kinase activity, whereas CDK2 bound to cyclin $\mathrm{E}$ has potent histone $\mathrm{H} 1$ kinase activity $(19,20,29,30)$. D cyclins are expressed throughout $\mathrm{G}_{1}$, whereas cyclin $\mathrm{E}$ (and hence, histone $\mathrm{H1}$ activity) appears only in late $G_{1}$. In late $\mathbf{G}_{1}$ and $S$ phase, cyclin A binds and activates CDK2, while in $G_{2}$ and $M$ cyclin A and B-type cyclins bind and activate CDK1 and 2; all of these cyclin-CDK complexes phosphorylate histone $\mathrm{H} 1$. Hence, it is not surprising that MAb 12D11 stains a lower percentage of cells than MIB-1/Ki-67 in nonneo- 
plastic proliferative tissues since $12 \mathrm{D} 11$ should react with cells from late $G_{1}$ through $G_{2}-M$, whereas MIB-1 stains throughout the entire cell cycle. In a quantitative study comparing 12D11 and MIB-1 staining in gynecologic tract lesions, the mean proportion of positively stained cells was also higher in MIB-1- compared with 12D11stained sections in normal squamous epithelium and in all grades of squamous intraepithelial lesions; the relationship of the 12D11 labeling index to the MIB-1 index was statistically highly significant (manuscript submitted).

A number of small molecules with CDKinhibitory activity have been isolated, some of which are being tested as anti-cancer agents (3134). Two of these, flavopiridol and 7-hydroxystaurosporine, show promise in early clinical trials (Senderowicz MD, National Cancer Institute, personal communication). In preliminary studies, we have found loss of MAb 12D11 reactivity upon treatment with the CDK inhibitor flavopiridol in a carcinoma from a patient with a strong clinical response to the drug (unpublished data). Furthermore, the correlation of prognosis with specific aberrations in CDK pathways in certain human tumors suggests a case for MAb 12D11 as a potentially useful prognostic marker. For example, breast carcinomas that aberrantly overexpress cyclin E have been shown to have a worse prognosis $(35,36)$. Because cyclin E activates CDK2, which possesses potent histone $\mathrm{H} 1$ kinase activity, this subset of breast cancers might be expected to demonstrate extensive MAb 12D11 staining. In contrast, breast carcinomas that overexpress cyclin D1 (which activates CDKs 4 and 6 , which lack significant histone H1 kinase activity) have been shown in two studies to have an improved prognosis $(35,37)$. These tumors would be expected to have less extensive MAb $12 \mathrm{D} 11$ staining than would cyclin E-overexpressing tumors.

Consistent with a possible role as a prognostic marker was the staining by MAb 12D11 of a case of cribriform intraductal mammary carcinoma and adjacent invasive carcinoma. Increased staining by MAb 12D11 in nests of infiltrating mammary carcinoma compared with adjacent cribriform intraductal carcinoma suggests that increased histone $\mathrm{H} 1$ phosphorylation may correlate with progression from in situ to invasive carcinoma in some tumor types. This may reflect an enhanced proliferation rate in invasive compared with in situ carcinoma, but alternatively could result from aberrations in expression of cyclins, CDK inhibitors, and other regulatory factors associated with invasive but not in situ carcinomas. Further studies are in progress to test this hypothesis.

\section{REFERENCES}

1. Gerdes J, Lemke H, Baisch H, Wacker HH, Schwab U, Stein H. Cell cycle analysis of a cell proliferation-associated human nuclear antigen defined by the monoclonal antibody Ki-67. J Immunol 1984;133:1710-5.

2. Yu CC, Filipe MI. Update on proliferation-associated antibodies applicable to formalin-fixed paraffin-embedded tissue and their clinical applications. Histochem J 1993;25:843-53.

3. Holden JA, Snow GW, Perkins SL, Jolles CJ, Kjeldsberg CR. Immunohistochemical staining for DNA topoisomerase II in frozen and formalin-fixed, paraffin-embedded, human tissues. Mod Pathol 1994;7:829-34.

4. Dutta A, Chandra R, Leiter LM, Lester S. Cyclins as markers of tumor proliferation: immunocytochemical studies in breast cancer: Proc Natl Acad Sci U S A 1995;92:5386-90.

5. Bravo R, Macdonald-Bravo H. Existence of two populations of cyclin/proliferating cell nuclear antigen during the cell cycle. Association with DNA replication sites. J Cell Biol 1987;105:1549-54.

6. Gao CY, Zelenka PS. Cyclins, cyclin-dependent kinases and differentiation. Bioessays 1997;19:307-15.

7. Bresnahan WA, Boldogh I, Ma T, Albrecht T, Thompson EA. Cyclin E/Cdk2 activity is controlled by different mechanisms in the $G_{0}$ and $G_{1}$ phases of the cell cycle. Cell Growth Differ 1996;7:1283-90.

8. Dobashi Y, Kudoh T, Matsumine A, Toyoshima K, Akiyama T. Constitutive overexpression of CDK2 inhibits neuronal differentiation of rat pheochromocytoma PC12 cells. J Biol Chem 1995;270:23031-7.

9. Smith E, Frenkel B, Schlegel R, Giordano A, Lian JB, Stein JL, Stein GS. Expression of cell cycle regulatory factors in differentiating osteoblasts: postproliferative up-regulation of cyclins B and E. Cancer Res 1995;55:5019-24.

10. Rieber M, Rieber MS. Cyclin-dependent kinase 2 and cyclin A interaction with E2F are targets for tyrosine induction of B16 melanoma terminal differentiation. Cell Growth Differ 1994;5:1339-46.

11. Rao SS, Kohtz DS. Positive and negative regulation of D-type cyclin expression in skeletal myoblasts by basic fibroblast growth factor and transforming growth factor beta. A role for cyclin D1 in control of myoblast differentiation. J Biol Chem 1995;270:4093-100.

12. Cole F, Fasy TM, Rao SS, dePeralto MA, Kohtz DS. Growth factors which repress myoblast differentiation sustain phosphorylation of histone H1. J Biol Chem 1993;268:1580-5.

13. Ravitz MJ, Wenner CE. Cyclin-dependent kinase regulation during G1 phase and cell cycle regulation by TGF-beta. Adv Cancer Res 1997;71:165-207.

14. Weinberg RA. The retinoblastoma protein and cell cycle control. Cell 1995;81:323-30.

15. Sherr CJ. Cancer cell cycles. Science 1996;274:1672-7.

16. King RW, Jackson PK, Kirschner MW. Mitosis in transition. Cell 1994;79:563-71.

17. Hunter T, Pines J. Cyclins and cancer II: cyclin D and CDK inhibitors come of age. Cell 1994;79:573-82.

18. Talasz $H$, Helliger $W$, Puschendorf $B$, Lindner $H$. In vivo phosphorylation of histone $\mathrm{H} 1$ variants during the cell cycle. Biochemistry 1996;35:1761-7.

19. Arion D, Meijer L, Brizuela L, Beach D. cdc2 is a component of the $\mathrm{M}$ phase-specific histone $\mathrm{H} 1$ kinase: evidence for identity with MPF. Cell 1988;55:371-8.

20. Labbe JC, Picard A, Peaucellier G, Cavadore JC, Nurse P, Doree M. Purification of MPF from starfish: identification as the $\mathrm{H} 1$ histone kinase p34cdc2 and a possible mechanism for its periodic activation. Cell 1989;57:253-63.

21. Shi SR, Cote RJ, Taylor CR. Antigen retrieval immunohistochemistry: past, present, and future. J Histochem Cytochem 1997;45:327-43. 
22. Levine DS, Haggitt RC. In: Sternberg SS, ed. Histology for pathologists. New York: Raven; 1992. p. 576-7.

23. Warnke RA, Weiss LM, Chan JKC, Cleary ML, Dorfman RF. In: Atlas of tumor pathology. 3rd series, Fascicle 14: Tumors of the lymph nodes and spleen. Washington, D.C.: Armed Forces Institute of Pathology; 1995. p. 3-5.

24. Schwartzendruber DC, Congdon CC. Electron microscope observations on tingible body macrophages in mouse spleen. J Cell Biol 1963;19:641-6.

25. Ellison DJ, Nathwani BN, Cho SY, Martin SE. Interfollicular small lymphocytic lymphoma. The diagnostic significance of pseudofollicles. Hum Pathol 1989;20:1108-18.

26. Matsushime H, Ewen ME, Strom DK, Kato J-Y, Hanks SK, Roussel MF, Sherr CJ. Identification and properties of an atypical catalytic subunit (p34PSK-J3/Cdk4) for mammalian D type G1 cyclins. Cell 1992;71:323-34.

27. Meyerson M, Harlow E. Identification of G1 kinase activity for Cdk6, a novel cyclin D partner. Mol Cell Biol 1994;14: 2077-86.

28. Koff A, Giordano A, Desai D, Yamashita K, Harper JW, Elledge S, et al. Formation and activation of a cyclin E-Cdk2 complex during the G1 phase of the human cell cycle. Science 1992;257:1689-94.

29. Koff A, Cross F, Fisher A, Schumacher J, Leguellec K, Philippe $\mathrm{M}$, et al. Human cyclin E, a new cyclin that interacts with two members of the CDC2 gene family. Cell 1991;66:1217-28.

30. Pines J, Hunter T. Human cyclin A is adenovirus Elaassociated protein p60 and behaves differently from cyclin B. Nature 1990;346:760-3.
31. Carlson BA, Dubay MM, Sausville EA, Brizuela L, Worland PJ. Flavopiridol induces G1 arrest with inhibition of cyclindependent kinase (Cdk2) and Cdk4 in human breast carcinoma cells. Cancer Res 1996;56:2473-8.

32. De Azevedo WF, Mueller-Dieckmann HJ, Schulze-Gahmen U, Worland PJ, Sausville E, Kim SH. Structural basis for specificity and potency of a flavonoid inhibitor of human CDK2, a cell cycle kinase. Proc Natl Acad Sci U S A 1996;93: 2735-40.

33. Kawakami K, Futami H, Takahara J, Yamaguchi K. UCN-01, 7 hydroxyl-staurosporine, inhibits kinase activity of cyclindependent kinases and reduced the phosphorylation of the retinoblastoma susceptibility gene product in A549 human lung cancer cell line. Biochem Biophys Res Commun 1996; 219:778-83.

34. Kitagawa M, Higashi H, Takahashi IS, Okabe T, Ogino H, Taya Y, et al. A cyclin-dependent kinase inhibitor, butyrolactone I, inhibits phosphorylation of RB protein and cell cycle progression. Oncogene 1994;9:2549-57.

35. Nielsen NH, Emdin SO, Cajander J, Landberg G. Deregulation of cyclin E and D1 in breast cancer is associated with inactivation of the retinoblastoma protein. Oncogene 1997; 14:295-304.

36. Nielsen NJ, Arnerlov C, Emdin SO, Landberg G. Cyclin E overexpression, a negative prognostic factor in breast cancer with strong correlation to oestrogen receptor status. Br J Cancer 1996;74:874-80.

37. Gillett C, Smith P, Gregory W, Richards M, Millis R, Peters G, Barnes D. Cyclin D1 and prognosis in human breast cancer. Int J Cancer 1996;69:92-9.

\section{Book Review}

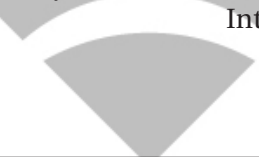

Sun T: Flow Cytometric Analysis of Hematologic Neoplasms. A Color Atlas and Text, 2nd ed, 296 pp, Philadelphia, Lippincott Williams \& Wilkins, 2002 (\$169.00).

This is the second completely revised and updated edition of Dr. Sun's book of flow cytometry (FCM) applied to the diagnostic study of lymphomas and leukemias. It consists of two distinct parts: an introductory part comprising chapters on the technical aspects of FCM and other diagnostic techniques used in the work-up of hematopathologic diseases, as well the new classifications; and the second part, titled Clinical Application, consisting of 38 case studies. The book shows that flow cytometry has become an invaluable part of the laboratory work-up of lymph node and bone marrow biopsies. At the same time the book clearly shows that FCM is not 'an independent diagnostic tool,' repeatedly emphasizing that FMC data should be interpreted only in the context of other laboratory and clinical data.

The case-study approach to teaching FMC is a very efficient way of demonstrating the clinical value of this technique. The cases are well chosen and instructive and almost all illustrate some valuable diagnostic points. The data for each case include flow histograms and countergrams, corresponding color figures of hematologic or pathologic findings, and, whenever indicated, immunohistochemical, molecular, or cytogenetic findings. Readers looking for quick review will appreciate the summary tables of salient features for each entity under discussion. References for each case are up to date.

The book will be used mostly by fellows and residents in pathology and hematology, but I would also recommend it to anybody else trying to learn FMC hematopathology. The book could be used as a reference by diagnostic hematopathologists as well.

\author{
Marin Nola \\ University of Nebraska Medical Center \\ Omaha, Nebraska
}

